\title{
The Effect of Local Fuse on Behavior of Concentrically Braced Frame by a Numerical Study
}

\author{
Ali Kachooee ${ }^{a *}$, Mohammad Ali Kafi ${ }^{b}$, Mohsen Gerami ${ }^{b}$ \\ ${ }^{a}$ Ph.D Student, Faculty of Civil Engineering, Semnan University, Semnan, Iran. \\ ${ }^{b}$ Associate professor, Faculty of Civil Engineering, Semnan University, Semnan, Iran.
}

Received 20 January 2018; Accepted 28 February 2018

\begin{abstract}
The concentrically braced frames (CBFs) are one of the most widely used lateral load-resisting systems. Seismic performance of these structures has a weakness that is due to the brace buckling at a lower loading than the ultimate compressive loading capacity. In this paper, attempt is made to enhance the seismic response of CBFs through utilizing a local fuse. For this purpose, first the formulation of fuse area and length are presented. Then based on this formulation, several numerical models have been built and analyzed to examine the effect of implementing this fuse on seismic response of CBFs. From the analyses results, it is found that if the reduced cross-section fuse (RCF) is properly designed and also the end of brace is fixed, the CBFs with equal energy dissipation capacity, that are equipped with this fuse exhibit a better ductility than the customary CBFs.
\end{abstract}

Keywords: Concentrically Braced Frame; Reduced Cross-Section Fuse; Ductility; Energy Dissipation Capacity.

\section{Introduction}

The concentrically braced frame $(\mathrm{CBF})$ structures are one of the most popular lateral load-resisting systems. The most important feature of these structures is their high stiffness and strength. Against low ductility of these structures there is an important concern which is due to the buckling of compressive member before reaching the nonlinear level and energy dissipation. Since loading capacity of the compressive member decreases after buckling, the hysteresis curve becomes asymmetric and then the energy dissipation is not well performed. In this regard, many studies have been performed by various researchers for improving the CBFs seismic response. In the following, some of them have been explained.

Friction damped braced frame (FDBF) was introduced by Pall and Marsh [1] for modifying the CBFs performance. In these structures, a friction element has been used at the intersection of X-braces element. The general conclusion of Pall and Marsh [1] studies showed that application of these cheap friction dampers in CBFs would greatly increase their seismic strength. In addition, this damper prevents the major element from damage when the structures are subjected to intense seismic excitations. In this case all of the damage is concentrated on the friction damper. Another lateral load resisting system for enhancing the CBF's ductility and energy dissipation capacity is yielding damped braced frame (YDBF). First, this structure system was introduced by Jurukovski et al. [2]. YDBF has a shape similar to that of FDBF but in YDBF, a rectangular steel frame is used at the intersection of X-braces element. In YDBF, while the structure is subjected to intense earthquake none of the fundamental structural elements are damaged. In these structures yielding mechanism is related to the yielding of rectangular middle frame and then is continued by yielding of the braces. The experimental studies of Jurukovski et al. [2] has demonstrated a better ductility and energy dissipation capacity of YDBF

* Corresponding author: ali.kachooee@semnan.ac.ir

$>$ This is an open access article under the CC-BY license (https://creativecommons.org/licenses/by/4.0/).

(C) Authors retain all copyrights. 
than those of the steel moment frame (SMF). In continuation, studying the YDBF, Sabouri and Roufegarinejad [3], investigated the effects of middle frame dimension and the type of beam-column connection on seismic response of YDBF. The results of this numerical study showed that increasing the middle frame dimension could improve ductility and energy dissipation capacity of YDBF to a certain extent and after that by increasing the middle frame dimension the mentioned response of YDBF would decrease. Another conclusion of this research was that the beam-column connection has not any impact on the YDBF seismic response. This implies that all of the nonlinear displacement is concentrated on the middle frame and braces, and the other structural elements remain intact. Sabouri and Payandehjoo [4] through utilizing the YDBF idea introduced yielding damped braced core (YDBC). YDBC consists of a central steel plate that is located at the intersection of $\mathrm{X}$-braces and it could take different dimensions. On the basis of Sabouri and Payandehjoo's [4] numerical studies, this damper is yielded under sever seismic excitations that demonstrates its high energy dissipation capacity. Also energy dissipation in this system is due to the yielding and inelastic behavior of central core (steel plate).

Buckling restrained braces (BRBs) are one of the invented structural systems, which are used to modify the CBF's seismic behavior [5-8]. BRBs through use of braces with core and sheath have solved the major weakness of CBFs, that's compression member buckling. For this reason, in the CBF structures, ductility and energy dissipation capacity are undesirable. In return, BRBs have symmetric and stable hysteresis curve which result into significant ductility and energy dissipation capacity. Besides, in the BRBs all of the damages are collected uniformly in braces and other structural members remain safe.

An off-centre bracing system was introduced [9] for improving of CBF behavior. It basically consists of the nonstraight tension strut with an eccentricity designated as e. The midpoint is connected to the corner by the third member. Once the load is applied, all these three members are stretched, therefore, act in tension. As the load increases, the original geometry changes and a new formulation of equilibrium equations based on the new geometry is required. Therefore, the characteristics of such an off-centre system are geometrically nonlinear. In the recent decade, extensive research has been conducted on this structural system [10-11]. In one them [10], some numerical studies have been performed using ANSYS software on a frame with off-centre bracing system with optimum eccentricity and circular element created, called OBS_C_O model. In addition, other steel frame with diagonal bracing system and the same circular element is created, called DBS_C model. Furthermore, linear and nonlinear behavior of these steel frames are compared in order to introduce a new way of optimum performance for these dissipating elements. The obtained results revealed that using a ductile element or circular dissipater for increasing the ductility of off-centre bracing system and centric bracing system is useful. Finally, higher ductility and more energy dissipation led to more appropriate behavior in the OBS_C_O model compared to DBS_C model.

D'Aniello et al. [12] performed several studies to improve CBF structures seismic performance. In one of them [12], a numerical study to improve chevron braced frame seismic performance so that its energy dissipation occurred through tension yielding of braces, has been carried out. In this study, the $\mathrm{k}_{\mathrm{f}}$ parameter was examined. $\mathrm{k}_{\mathrm{f}}$ is the ratio of flexural stiffness of intersection beam with braces to the axial stiffness of braces. The general result of this study was that by increasing the $\mathrm{k}_{\mathrm{f}}$ when braces are yielded, inter-story drift would decrease so that if $\mathrm{k}_{\mathrm{f}}$ be infinity, the yielding of braces would be tensional and the inter-story drift would be between $0.1 \%$ and $0.3 \%$, depending on the braces tilt. Also a $\mathrm{k}_{\mathrm{f}}$ equal to 0.1 is a limit state. If $\mathrm{k}_{\mathrm{f}}$ be larger than 0.1 the yielding of braces will be tensional and inter-story drift, depending on the brace's slope would be between $2 \%$ to $3 \%$. Finally if $\mathrm{k}_{\mathrm{f}}$ be smaller than 0.1 , the braces would not yield in tension and for the inter-story drift larger than $2 \%$ both of the braces would be in compression.

Kumar et al. [15] obtained optimum values of slenderness and aspect ratio of circular braces for best performance of $\mathrm{CBF}$ structures. From the results of this study it was found that for an aspect ratio equal to 10, no energy dissipation degradation happens before 5\% inter-story drift. This is due to the lack of early brace failure. Also based on the results of this study, by considering the energy dissipation capacity and ductility parameters, the maximum aspect ratio of circular braces should be reduced from 20 to 18.5 in the codes and guidelines.

A cast modular ductile bracing system (CMDB) as an alternative for the special CBF structures was introduced [1617]. In these structural systems use has been made of cast component at the middle and ends of the braces. A cruciform cross-section has been utilized for CMDB because this section increases energy dissipation capacity and low cycle fatigue life and in turn they cause reduced brace failure probability. Also in a study [17], the axial and flexural ratios of cast component elements to braces elements were examined and the optimum ratio is taken for these parameters. The most effective of these ratios is a little less than 1 for the axial ratio and a little more than 1 for the flexural ratio, respectively.

Legeron et al. [18] and Desjardins et al. [19] performed experimental and numerical researches on CBF with angle member braces, to improve these structures' seismic performance and also prevent strengthened connections of their braced frames. In study of Legeron et al. [18], two fuses are devised at the ends of diagonal members where they had lower tensional capacity than the connection. Also in this study the best distribution configuration and insertion of fuses in the braces is achieved. The result of this experimental study showed that the connection strengthening is not necessary 
for the braces using this type of fuses. This is very economical and reduces the construction cost. Also this study demonstrated that the braces equipped with this type of fuse have a stable response and good ductility with a good compressive strength, under cyclic loading. Bonetti [20] have introduced two models for modification of special CBFs. in one of these models use has been made of an oval shaped fuse. In this model the tensile capacity depends on the fuse area and the compression capacity not only depends on the fuse area but also is dependent on the fuse length. The experimental study of Bonetti [20] for this model displayed restricted performance in energy dissipation. The second model of Bonetti [20] is a brace composite element that consists of metal bars embedded in a polymer matrix, which is confined by carbon fiber reinforced polymers. In this model, the tensile capacity is equal to that of the bars. The compressive strength is defined by the buckling capacity of the metal bars. Due to the slenderness of the bars, a confined polymer matrix is used to provide lateral restraint and maintain the axial stiffness of the bars under compressive loads. The experimental results of this model demonstrated that it could withstand large inelastic deformations and is able to significantly dissipate the energy.

Another method that has been developed as a substitute for conventional concentric braces is all-steel tube-in-tube buckling controlled brace that is called (TinT-BCB) [21-23]. The results of studies conducted by Seker and Shen [22] show that the hysteresis response of this brace was consistent and symmetrical under cyclic loading. The factors affecting the response of these braces include the friction between the two pods, the distance between the internal and external tubes, and the thickness ratio of the inner and outer tubes. Generally in this brace, optimal performance results from a system with smallest gap possible, low friction, and heavier outer tube.

In this paper, a type of fuse is introduced to improve the seismic response of CBFs. this fuse is fabricated through reducing the brace area at one of its end. Six 3D models are built in Abaqus 6.12 [24] software to examine the effect of this fuse on seismic behavior of CBFs. Also different fuse length sizes are implemented in the models so that the effects of fuse's length changes are perused through the responses. In continuation, this fuse and the corresponding numerical results are presented in detail.

\section{Introducing the Numerical Models, Material Properties and Load Patterns}

\subsection{The Base Model}

The prototype frame has been shown in Figure 1. In this frame which consists of chevron braces, the bay length is 5 $\mathrm{m}$, the height is $3.30 \mathrm{~m}$ and the diagonal length is $4.14 \mathrm{~m}$. As shown in Figure 1, the pinned type connection is chosen to connect the brace to frame, beam to column and frame to the ground. Because the entire inelastic deformation is accumulated in the braces under seismic excitation; it is assumed that the frame lateral seismic response depends solely on the brace's behavior. For this reason, just finite element study has been carried out for the braces. Also, as shown in Figure 2 and Table 1, the selected section of braces is comprised of two UPE120 profiles with $1 \mathrm{~cm}$ space between them.

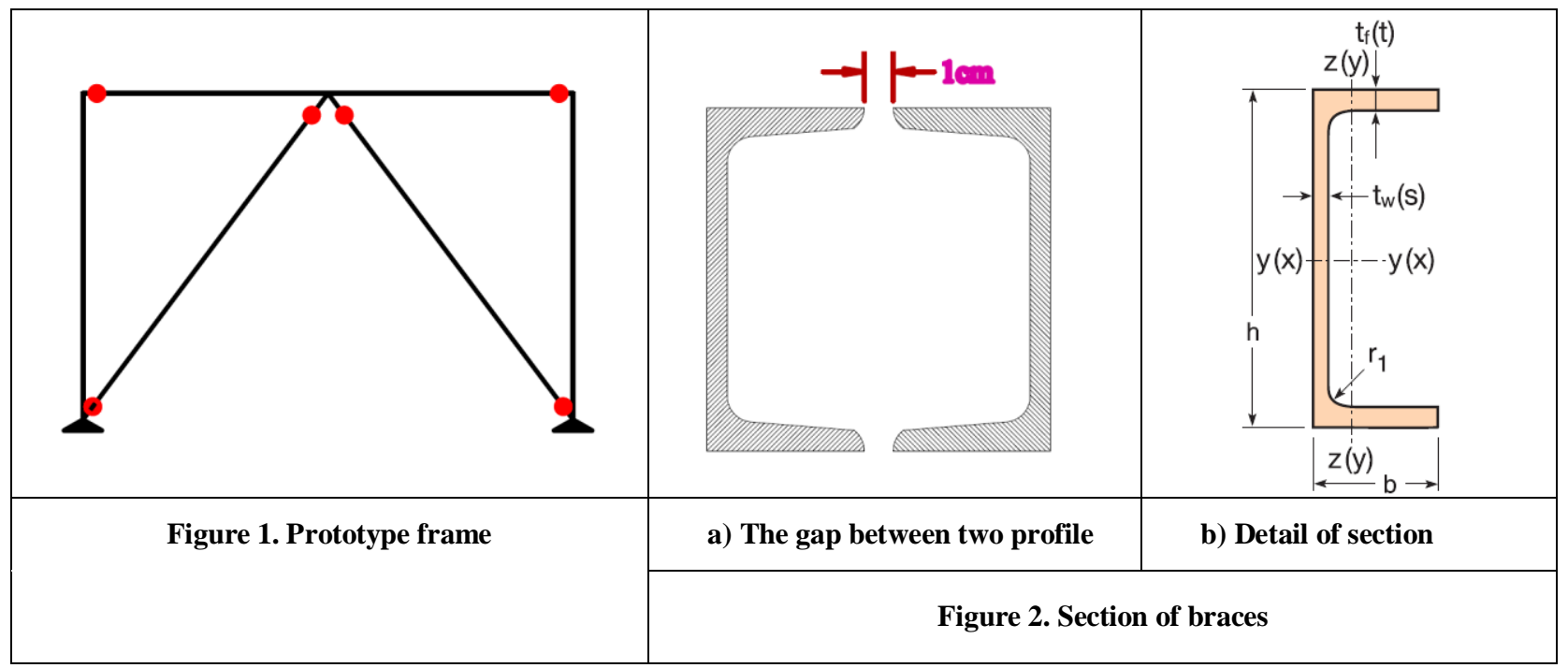

Table 1. Detail of the brace

\begin{tabular}{ccccccc}
\hline Profile name & $\mathbf{h}(\mathbf{m m})$ & $\mathbf{b}(\mathbf{m m})$ & $\mathbf{t}_{\mathbf{w}}(\mathbf{m m})$ & $\mathbf{t}_{\mathbf{f}}(\mathbf{m m})$ & $\mathbf{r}_{\mathbf{1}}(\mathbf{m m})$ & $\mathbf{A}\left(\mathbf{m m}^{2}\right)$ \\
\hline UPE120 & 120 & 60 & 5.0 & 8.0 & 12 & 1540 \\
\hline
\end{tabular}

Two UPE12 sections are connected together based on AISC [25] so that they have an integrated action. As shown in Figure 3, the lengths of end connection plates are $18 \mathrm{~cm}$ and they are $5 \mathrm{~cm}$ for the middle plates. Also the bare space between connection plates is $48 \mathrm{~cm}$. in addition, based on AISC [25], no connection plate should be inserted within the 
middle quarter length region. This length is $103 \mathrm{~cm}$ in this study.

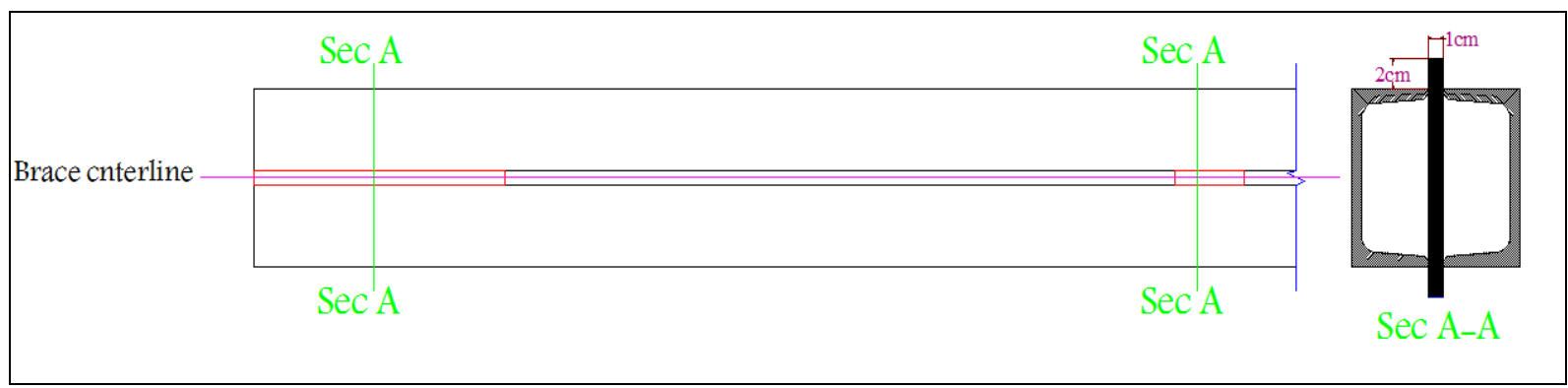

Figure 3. Connecting of UPE12 sections together

In continuation, the models with inserted reduced cross-section fuse (RCF) have been introduced. First, the numerical calculation of fuse area and length are explained.

\subsection{Fuse Area and Length Formulation}

In this project, the author performed experiments on SC pile that applied for the foundation of An Trung complex apartment in Da Nang city, Vietnam, the location of the project is shown in Figure 1. This project was designed as a twelve-stories building to provide the services to low-income people. Some requirements were given in design process, included reducing the cost of the project in general and foundation structure in particular. Based on the previous studies including the pros and cons of SCpile, the method using SCpile was chosen for support to the foundation structure of the projects.

\subsubsection{Fuse Area Formulation}

The aim of this study is that RCF yielding occurs of earlier than the bracing global buckling through utilizing the entire tensile and compressive capacities of RCF. For this reason the following equation is derived:

$$
\mathrm{P}_{\mathrm{u}, \text { fuse }} \leq \mathrm{P}_{\text {Cr,brace }}
$$

In Equation $1, \mathrm{P}_{\mathrm{u}}$ fuse is the final tensile capacity of RCF and $\mathrm{P}_{\mathrm{Cr} \text {,brace }}$ is the bracing global buckling capacity. $\mathrm{P}_{\mathrm{u}, \text { fuse }}$ is calculated according to Equation 2:

$$
\mathrm{P}_{\mathrm{u}, \text { fuse }}=\mathrm{A}_{\text {fuse }} \cdot \mathrm{F}_{\mathrm{u}, \text { fuse }}
$$

In the above equation, $A_{\text {fuse }}$ is the fuse area and $\mathrm{F}_{\mathrm{u} \text {,fuse }}$ is the final stress of the fuse material. According to Equations 1 and 2 , the fuse area is calculated based on the following equation:

$$
\mathrm{A}_{\text {fuse }} \leq \frac{\mathrm{P}_{\text {Cr,brace }}}{\mathrm{F}_{\mathrm{u} \text {,fuse }}}
$$

\subsubsection{Fuse Length Formulation}

According to Equation 4, the fuse slenderness, $\lambda_{\text {fuse }}$ should be lower than that of the brace, $\lambda_{\text {brace }}$, so that the fuse is not buckled before the brace:

$$
\lambda_{\text {fuse }} \leq \lambda_{\text {brace }}
$$

$\lambda_{\text {fuse }}$ and $\lambda_{\text {brace }}$ are calculated using Equations 5 and 6, respectively:

$$
\begin{aligned}
& \lambda_{\text {fuse }}=\frac{l_{\text {fuse }}}{r_{\text {fuse }}} \\
& \lambda_{\text {brace }}=\frac{l_{\text {brace }}}{r_{\text {brace }}}
\end{aligned}
$$

In the above equations, $l_{\text {fuse }}$ and $l_{\text {brace }}$ are the fuse length and brace length, respectively. Also $r_{\text {fuse }}$ and $r_{\text {brace }}$ are the radius of gyration for the fuse and brace, respectively. According to Equations 4-6, and considering that $\lambda_{\text {fuse }}$ could be calculated after drawing of $\mathrm{A}_{\text {fuse }}, \mathrm{l}_{\text {fuse }}$ could be obtained from Equation 7 :

$$
l_{\text {fuse }} \leq \frac{l_{\text {brace }} \cdot r_{\text {fuse }}}{r_{\text {brace }}}
$$




\subsection{Models with Introduced Fuse and Material Properties}

In this study, use has been made of St37 steel with Poisson ratio of 0.3 and elastic modulus (E) equal to 2000000 $\mathrm{Kg} / \mathrm{cm}^{2}$. The yielding and ultimate stresses are $2400 \mathrm{Kg} / \mathrm{cm}^{2}$ and $3700 \mathrm{Kg} / \mathrm{cm}^{2}$, respectively, for this material. Also the ultimate strain is equal to 0.1988. According to Figure 4, the F5 and F20 models are built to investigate the effect of RCF on CBF structures seismic response. Both models have an area equal to $22.6 \mathrm{~cm}^{2}$ based on Equation 3. Also based on Equation 7, the fuse lengths are 5 and $20 \mathrm{~cm}$ in F5 and F20 models, respectively. As shown in Figure 4, in both models the fuse element has been placed at $25 \mathrm{~cm}$ distance from one of the brace ends. Also a transition quadrant shape region has been considered between the fuse and the brace. In attention to different length values in the models, the effect of this parameter in cyclic response of numerical models has been perused. Also the 2U12-Fixed, F5-Fixed and F20-Fixed models that have fixed end-supports are built to investigate the effect of end condition on cyclic response of RCF models.

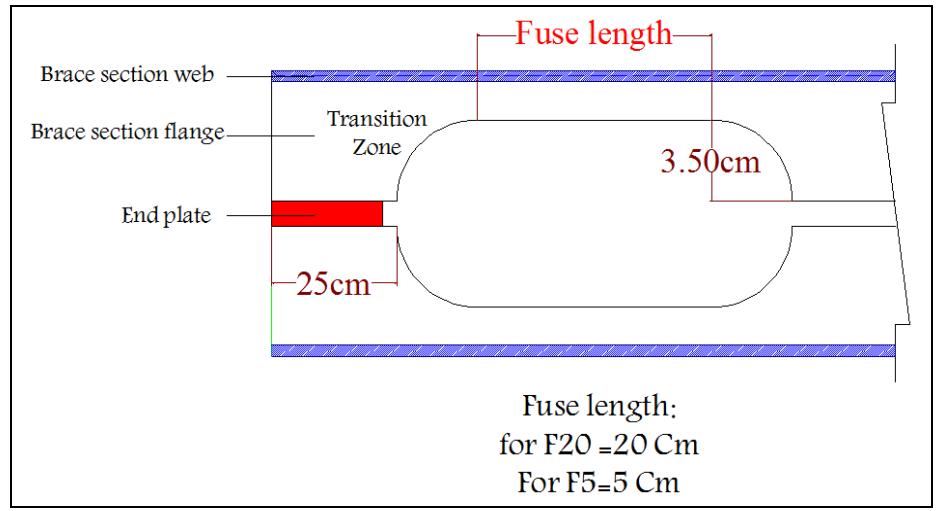

Figure 4. Top view of the Fuse details

\subsection{Model Setup}

According to Figure 5, the mentioned models have been introduced in the section 2.3, were built in ABAQUS 6.12 software [24] in order to perform the analyses.

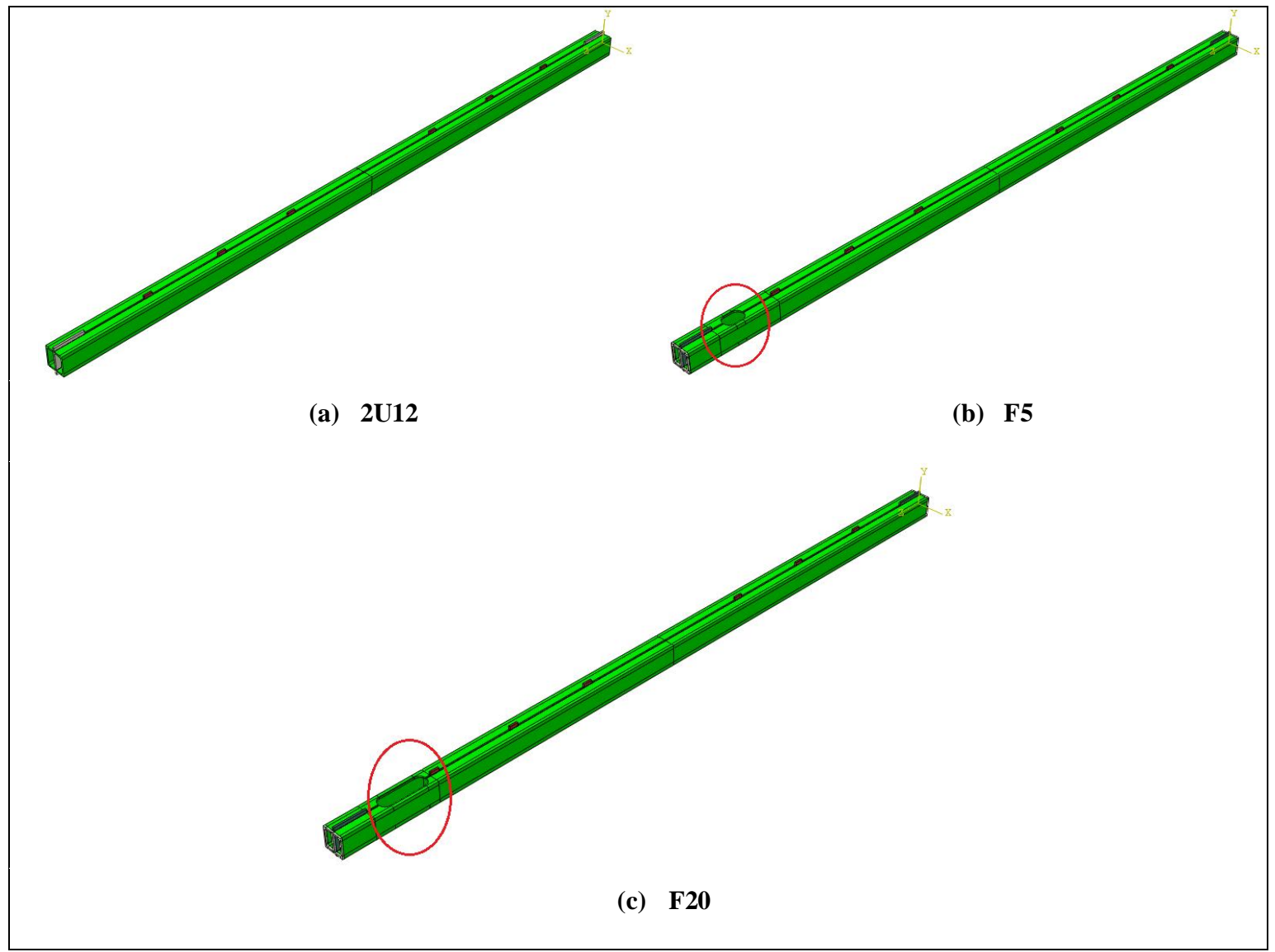

Figure 5. Studied numerical models 
All of the parts, for building the numerical models, were considered 3D deformable element. Also a fine mesh with size equal to $0.5 \mathrm{~cm}$ assigned to all of the parts. In addition, element mesh type of entire models is considered C3D8R. Also to create the pin end connection for 2U12, F5 and F20 models, according to Figure 6 (a) only the middle of the brace section has been tied. But, in accordance of Figure 6 (b), for other models (namely 2U12-Fixed, F5-Fixed and F20-Fixed models) all of the section points have been tied.

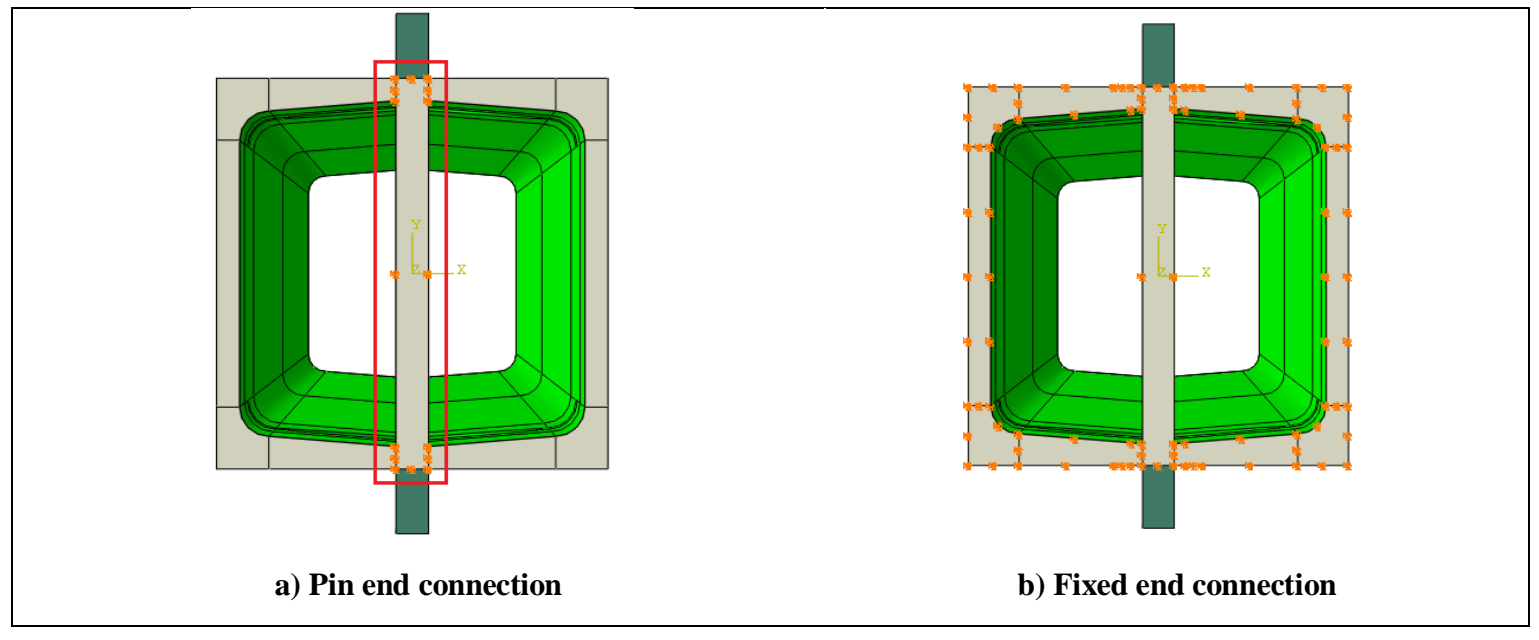

Figure 6. Types of the end connections of numerical models

\subsection{Load Pattern}

As seen in Figure 5(a)-(c), all models are built in Abaqus 12.1 finite element software. Then these models are subjected to a cyclic load as shown in Figure 7 to draw their corresponding hysteresis curves. In the next section, all of the models hysteresis curves are compared to each other to demonstrate the effect of RCF on seismic response of CBF structures.

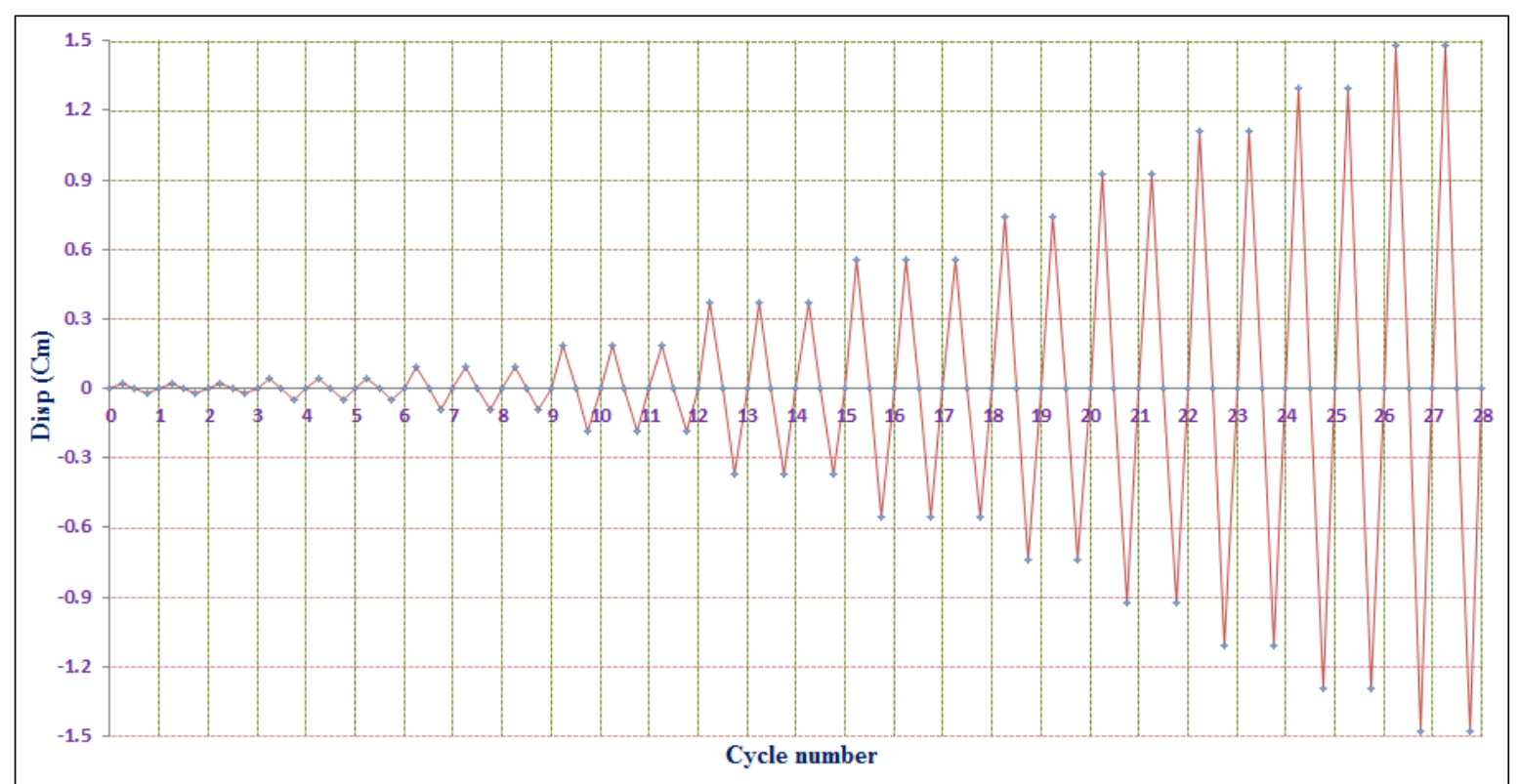

Figure 7. Load pattern

\section{The Analysis Results}

\subsection{The Hysteresis Curves of the Numerical Models}

In this section the axial load-axial displacement curves of structural models are illustrated. Hysteresis curve of $2 \mathrm{U} 12$ model is presented in Figure 8. As shown in it, 2U12 model both yielded and buckled at the same load equal to 81.6 tons. But based on the theoretical calculations, this model should have yielded at 81.6 tons and buckled at 83.6 tons. The reason for the difference between theoretical and analytical buckling capacities of this model is related to the changes in the steel elastic modulus before and after yielding. After yielding of steel, its elastic modulus decreases and according to the equation: $P_{C r}=\left(\pi^{2} . E\right) / \lambda^{2}$, also the buckling capacity of brace would reduce. In this study $\mathrm{E}_{\mathrm{p}}=0.003$. $\mathrm{E}_{\mathrm{e}} \mathrm{In}$ which $\mathrm{E}_{\mathrm{p}}$ is the steel plastic modulus and $\mathrm{E}_{-} \mathrm{e}$ is its elastic modulus. The plastic buckling capacity $\mathrm{P}_{-}(\mathrm{Cr}, \mathrm{plastic})$ of $2 \mathrm{U} 12$ model is significantly lower than its elastic buckling capacity, $\mathrm{P}_{\mathrm{Cr} \text {,elastic }}$. In $2 \mathrm{U} 12$ model, $\mathrm{P}_{\mathrm{Cr} \text {, plastic }}$ is equal to 250 
$\mathrm{kg}$. Therefore, as the brace load is highly greater than $\mathrm{P}_{\mathrm{Cr} \text {,plastic }}$ during yielding of this model, the brace would buckle immediately. This issue is very important and should be considered in design of all braces where their buckling capacity is greater than their yielding capacity.

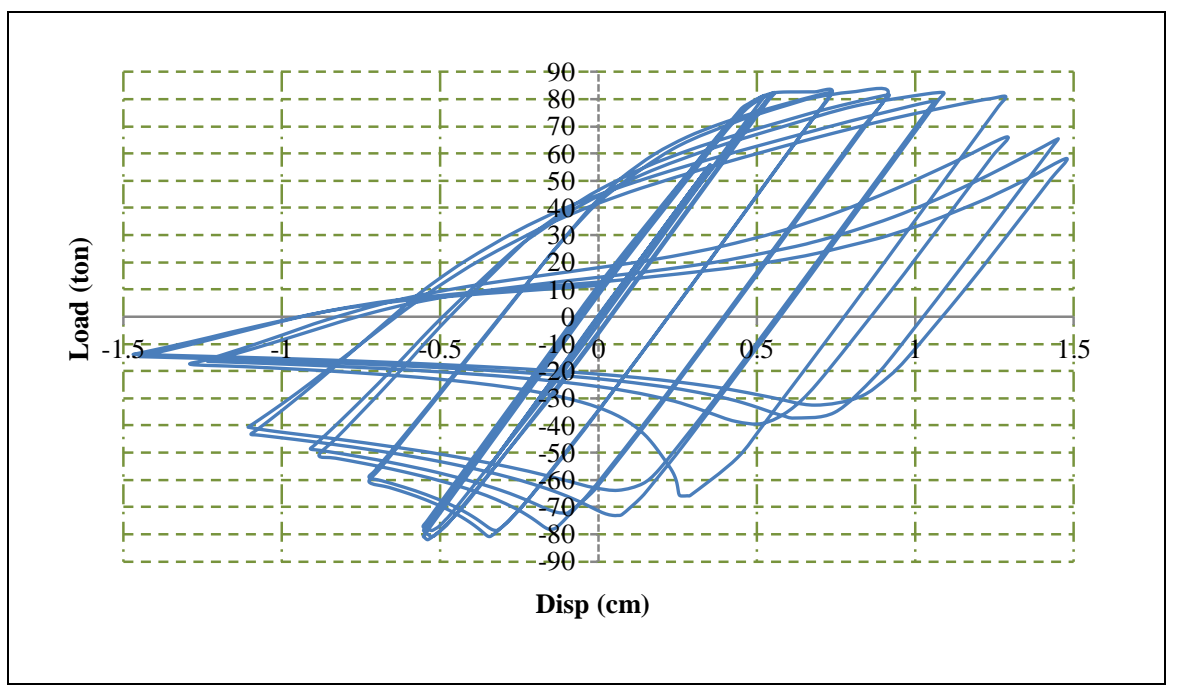

Figure 8. Load - Displacement curve of $2 \mathrm{U} 12$

Figures 9 and 10 represent the hysteresis curves of F20 and F5 models, respectively. According to these curves, both models yielded and buckled at 54.2 tons.

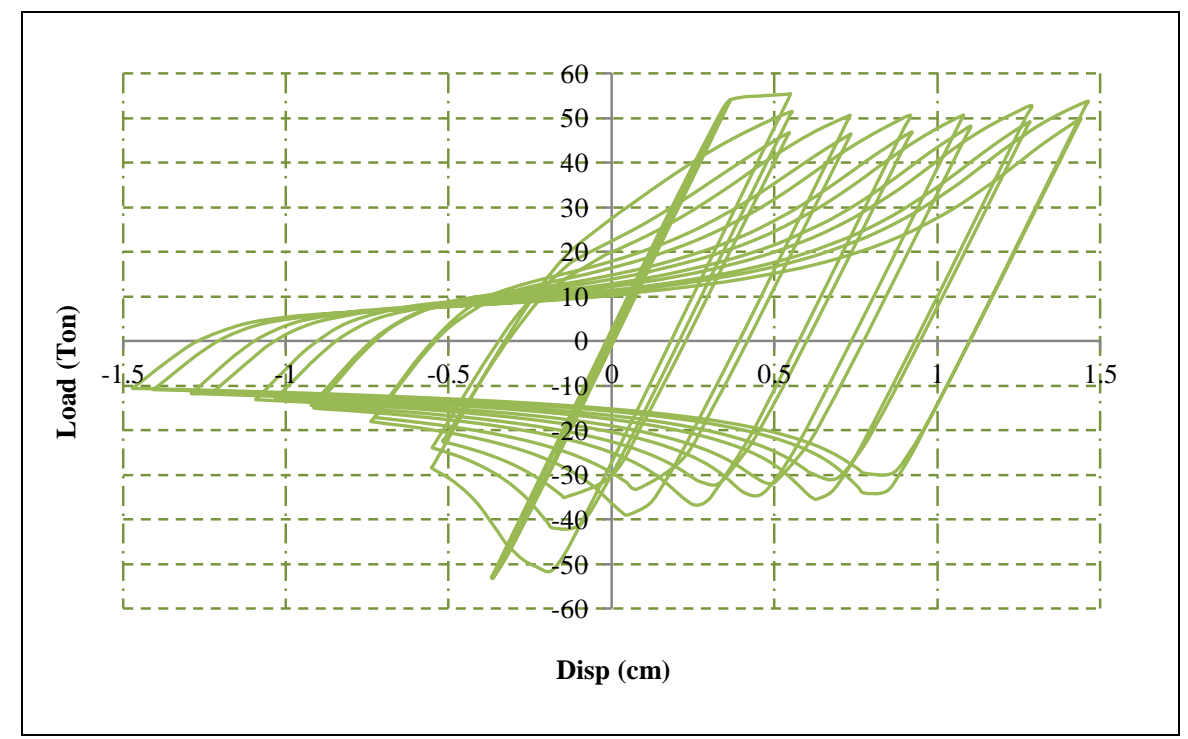

Figure 9. Load - Displacement curve of F20

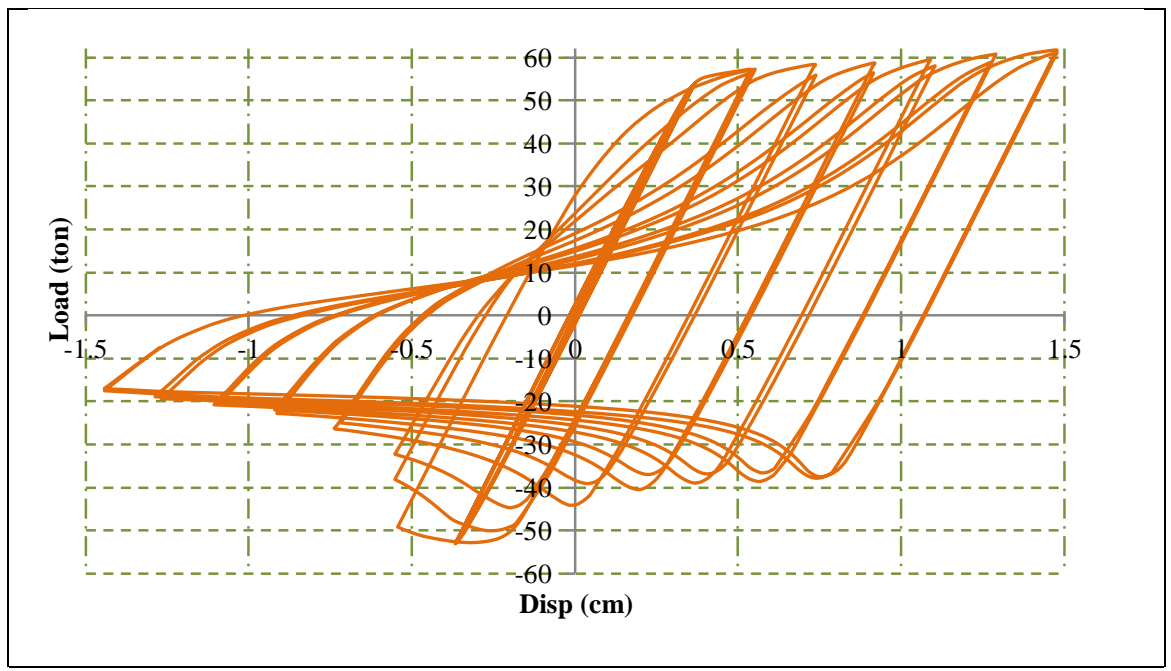

Figure 10. Load - Displacement curve of F5 
As shown in Figure 11, both models are unexpectedly buckled because buckling has occurred in the fuse region. The fuse lengths of the two models are selected based on Equation 7, in a way to prevent buckling of the fuse before the brace global buckling. As stated before, the reason for early fuse buckling lies in the reduced material stiffness after the fuse yielding. This issue causes that full advantage is not taken from the RCF's load bearing capacity. So, despite selection of a proper fuse length, changes in the materials stiffness after the fuse yielding, as an important parameter, causes early fuse buckling and thus not allowing the fuse to reach its ultimate loading bearing capacity.

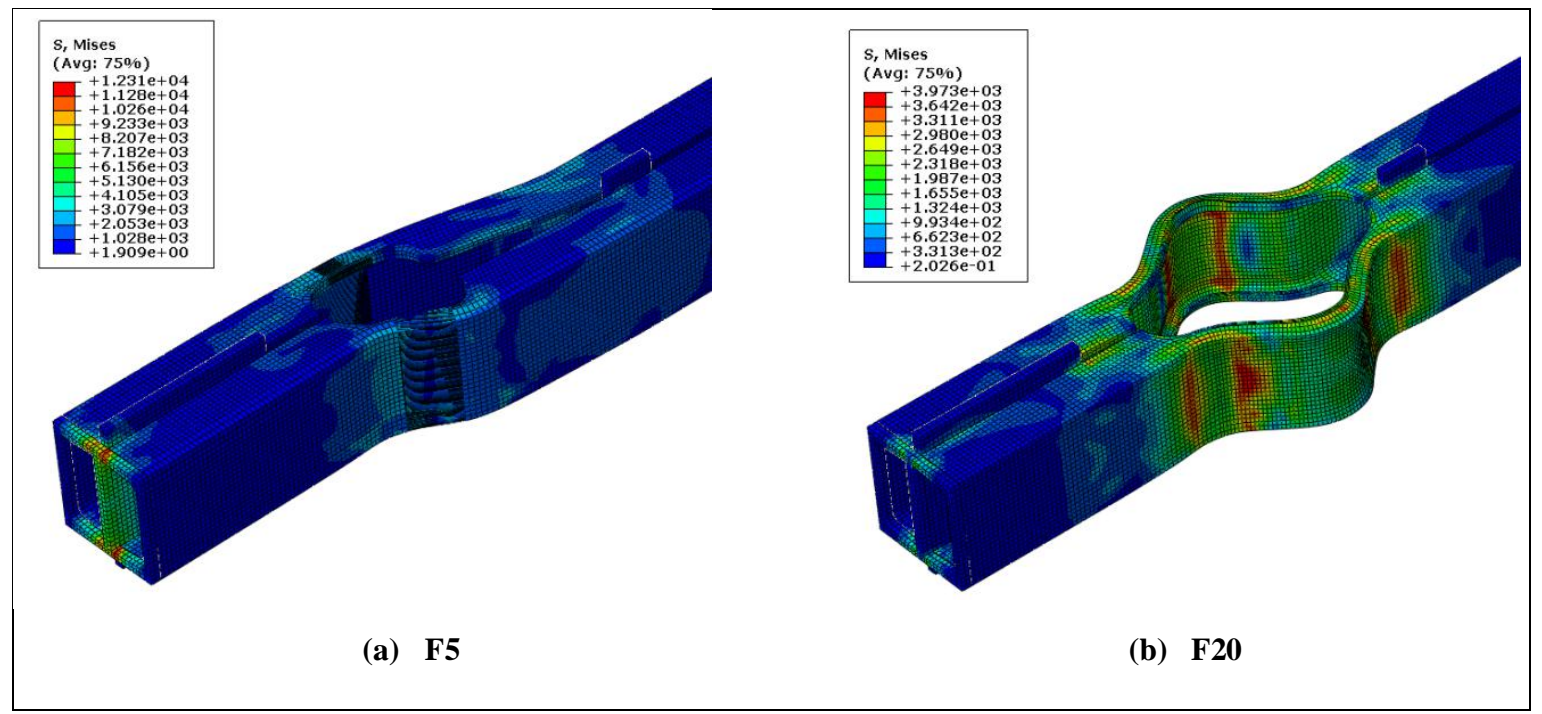

Figure 11. The process of fuse buckling in CRF models

\subsection{Comparison Between Hysteresis Curves of Numerical Models}

In Figure 12, hysteresis curves of 2U12, F20 and F5 have been overlapped to make comparison between their cyclic responses. As shown in Figure 12, generally during loading process the 2U12 model dissipated more energy than other models. The dissipated energy in 2U12 is 1049 tons.cm while it is 826 tons.cm and 726 tons.cm for F5 and F20, respectively. In the other words, the dissipated energy in F5 and F20 models is 79\% and 69\% of that in $2 \mathrm{U} 12$ model, respectively. The weak performance of F5 and F20 in energy dissipation is related to the early fuse buckling. In terms of ductility capacity, F20 and F5 have clearly exhibited better performance with respect to 2U12, because they yield sooner than it.

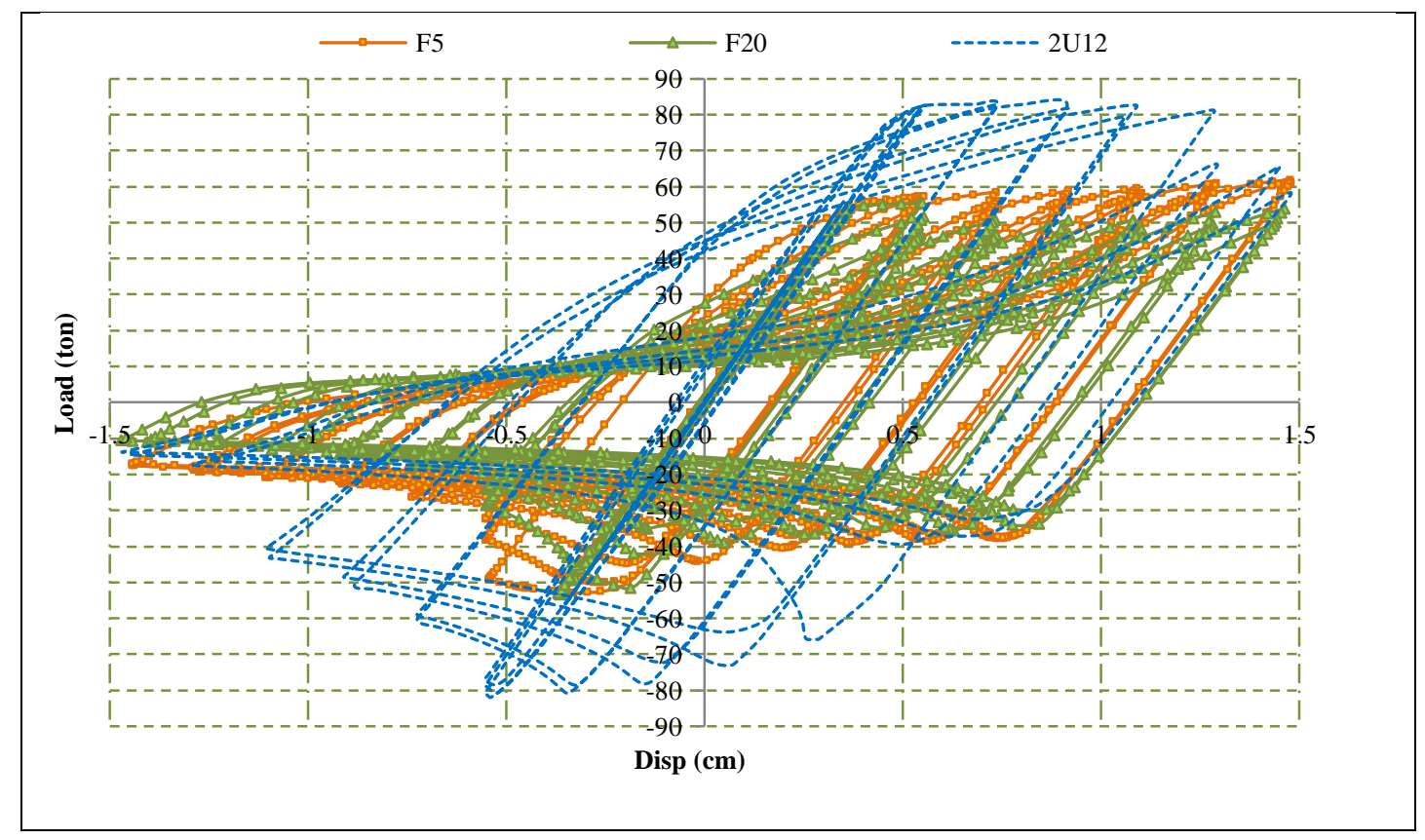

Figure 12. Comparison of studied models hysteresis curves

Now, the hysteresis curves of models, until fuse buckling of F5 and F20, are presented in Figure13 to demonstrate the condition of models together. As shown in this figure, F5 and F20 have significantly better performance than 2 U12 both in terms of energy dissipation capacity and ductility capacity. In this case, the value of dissipated energy for both 
F5 and F20 was 90 tons.cm but this was 30 tons.cm for 2U12. In fact, before fuse buckling the models with RCF had dissipated energy three times more than $2 \mathrm{U} 12$, which is a considerable value.

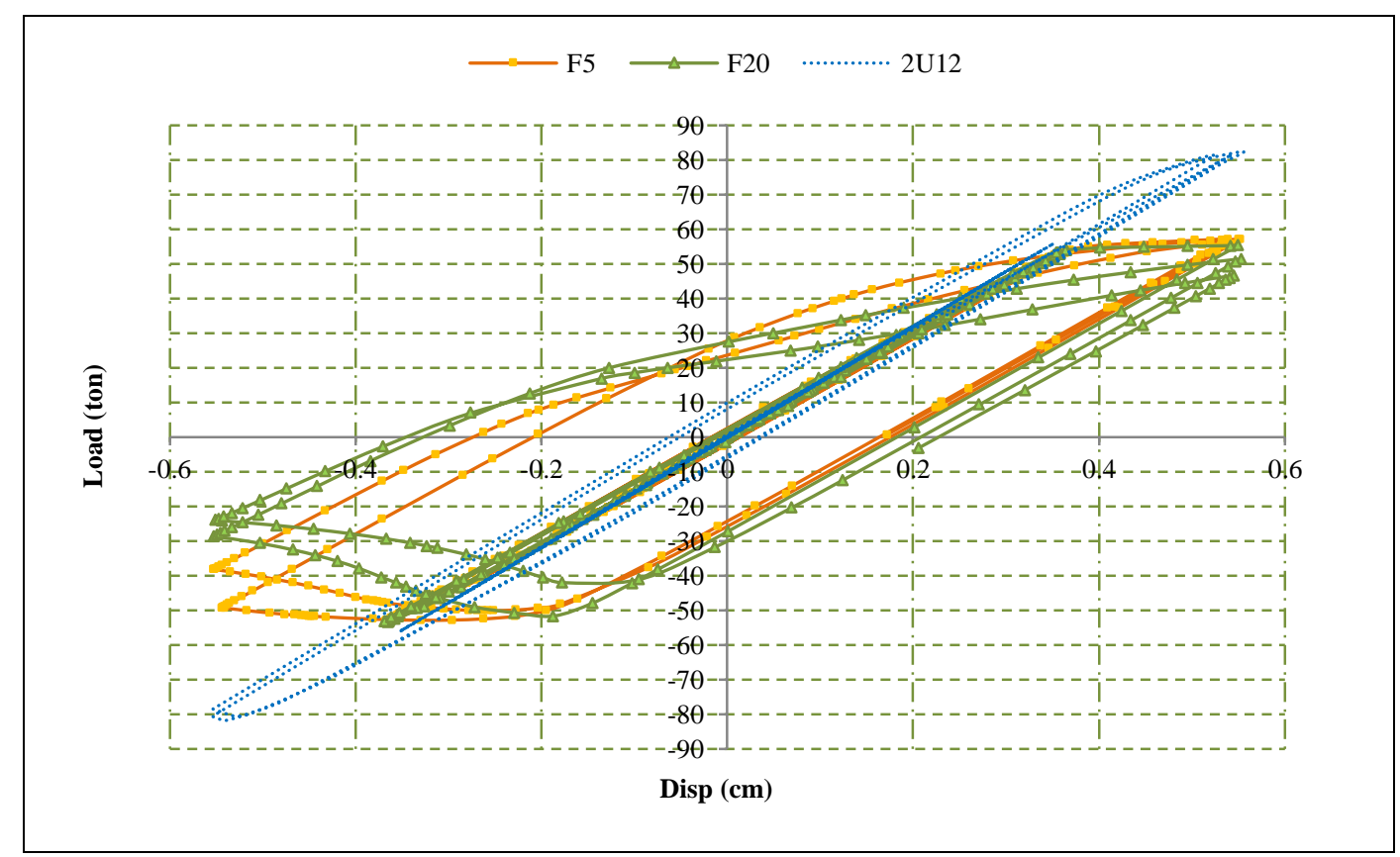

Figure 13. Comparison of studied models hysteresis curves until buckling of fuse in RCF models

As shown in Figures 12 and 13, to examine the effect of fuse length in cyclic response of analytical models with RCF, F5 and F20 have equal tension capacities until buckling, but after that F5 have tolerated higher tension loads. Also in the compression region, F5 has beard more loads than F20, both before and after the fuse buckling. In terms of energy dissipation capacity, both models have dissipated equal energy until buckling of models, but after it, F5 dissipated more energy than F20. So it could be concluded that energy dissipation capacity and loading capacity of models with RCF have been increased by reducing the fuse length.

In Figure 14 the equivalent plastic strain (PEEQ) parameter has been compared between F5 and F20 models for their critical points in accordance of Figure 15.

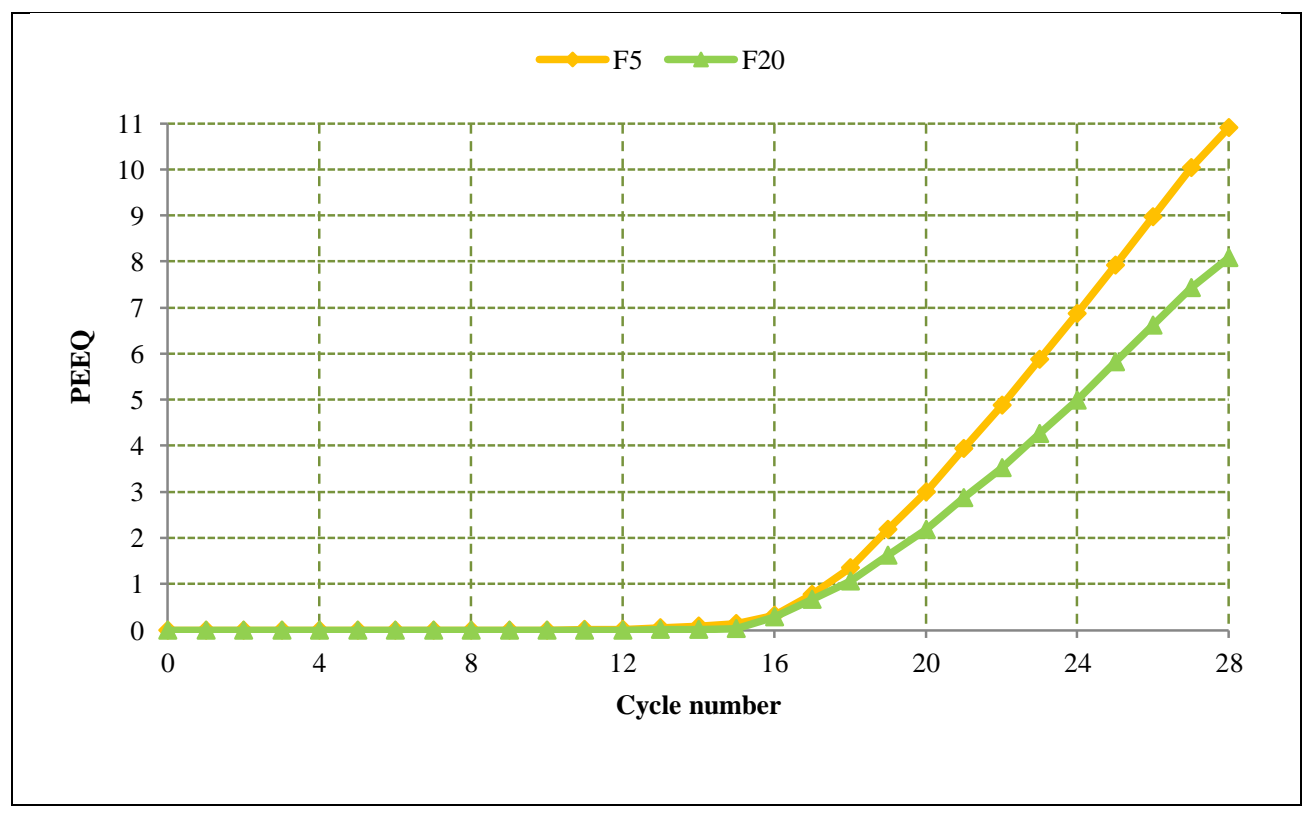

Figure 14. Comparison of PEEQ parameter between F5 and F20 models 


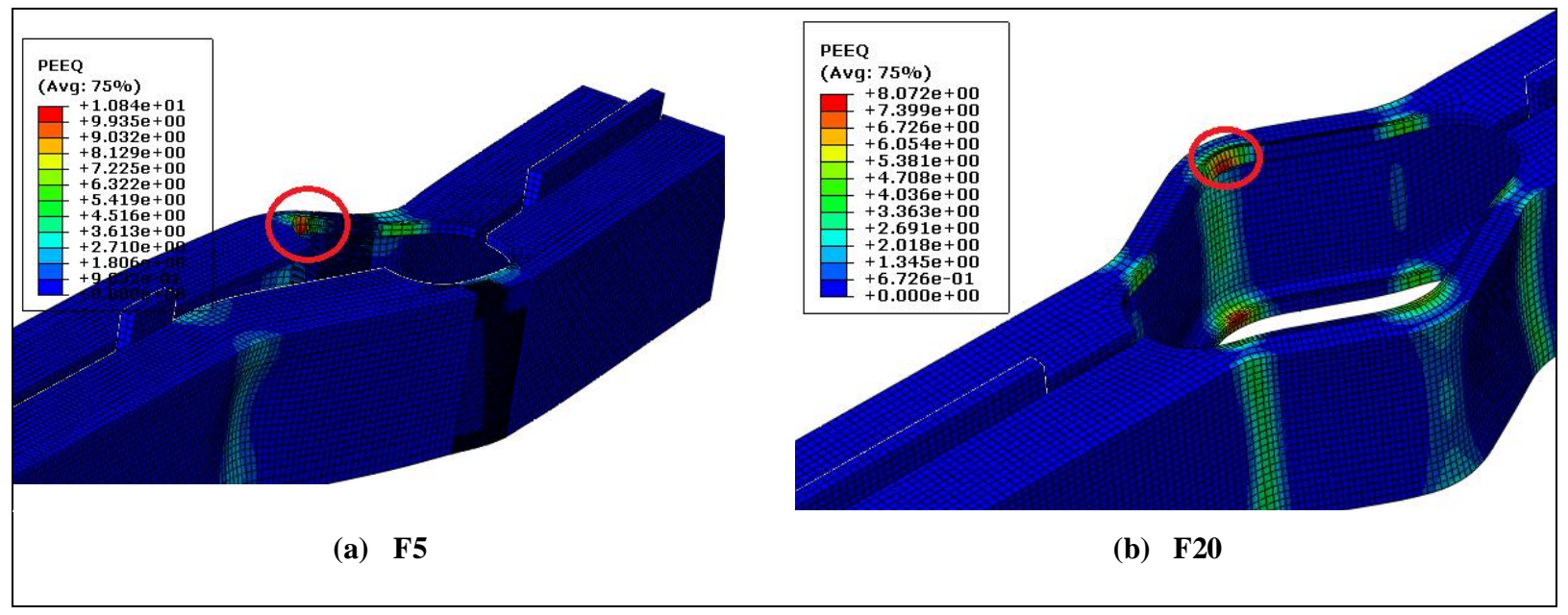

Figure 15. Critical points in the numerical models based on PEEQ parameter

PEEQ parameter has been used for determining of plastic points in the structural elements. When this parameter be more than zero it means that the point has been plastic. In accordance of Figure 14 the plasticity has been began from $10^{\text {th }}$ loading cycle in F5 model but in F20 model it has been happened from $13^{\text {th }}$ loading cycle. Also the PPEQ parameter in all of the loading cycle is bigger for F5 model than F20 model. In addition, by increasing the loading cycle, the intensity of plasticity has been increased more in F5 than F20 model. The maximum of PEEQ parameter is 10.9 in model F5 while this is $26 \%$ less in F20 model and is equal to 8.07. So based on the above description, this conclusion is gained that the longer length of fuse leads to the less intensity of the plasticity. In other words, the longer length of fuse is caused fuse reach later to its final plastic capacity and so fuse will be stop posterior.

\subsection{The Effect of end Condition on RCF Cyclic Response}

In this section the impact of end condition on RCF cyclic response is investigated. For this reason the models with names 2U12-Fixed, F5-Fixed and F20-Fixed are built in ABAQUS software. The difference between them and the primary models is their end condition. The end support conditions of the rudimental models were pinned and it was fixed for the latter models. Figure 16 compares between hysteresis curves of 2U12 and 2U12-Fixed. As shown in Figure 16 , both models yielded and buckled at the same load equal to 81.6 tons. Based on the theoretical computations, the buckling loads of 2U12 and 2U12-Fixed are 83.6 tons and 334.4 tons, respectively. But because of drastic reduction of $\mathrm{E}_{\mathrm{p}}$ with respect to $\mathrm{E}_{\mathrm{e}}$, the buckling capacity of them is greatly reduced and both have been buckled immediately after yielding. In this study $E_{p}=0.003$. $E_{e}$. Therefore according to the recent equation and the equation: $P_{-} C r=$ $\left(\pi^{\wedge} 2\right.$. E $) / \lambda^{\wedge} 2$, it is concluded that $\mathrm{P}_{\mathrm{Cr} \text {,plastic }}=0.003 . \mathrm{P}_{\text {Cr,elastic }}$. This issue is causes that 2U12-Fixed buckles at a load that is a quarter of $\mathrm{P}_{\text {cr.elastic. }}$ So $\mathrm{E}_{\mathrm{p}}$ should be considered in the buckling calculation of CBFs which have elastic buckling capacities greater than the yielding capacity. For these kinds of braces the buckling capacity must be considered equal with their yielding capacity, otherwise design of these structures would be entirely incorrect. Also the energy dissipation of models is the same and equal to 1049 tons.cm. However the process of energy dissipation is different between models. 2U12 dissipated more energy at the first displacement cycles after buckling, than 2U12-Fixed. But at increased displacement cycles, 2U12-Fixed could dissipate more energy than 2U12. The reason of it lies in the fact that the compression capacity of 2U12 decreased rapidly after buckling with respect to that of 2U12-Fixed, and that is due to increased rate of $2 \mathrm{U} 12$ lateral displacement with respect to that of 2U12-Fixed, with increasing displacement cycles. 


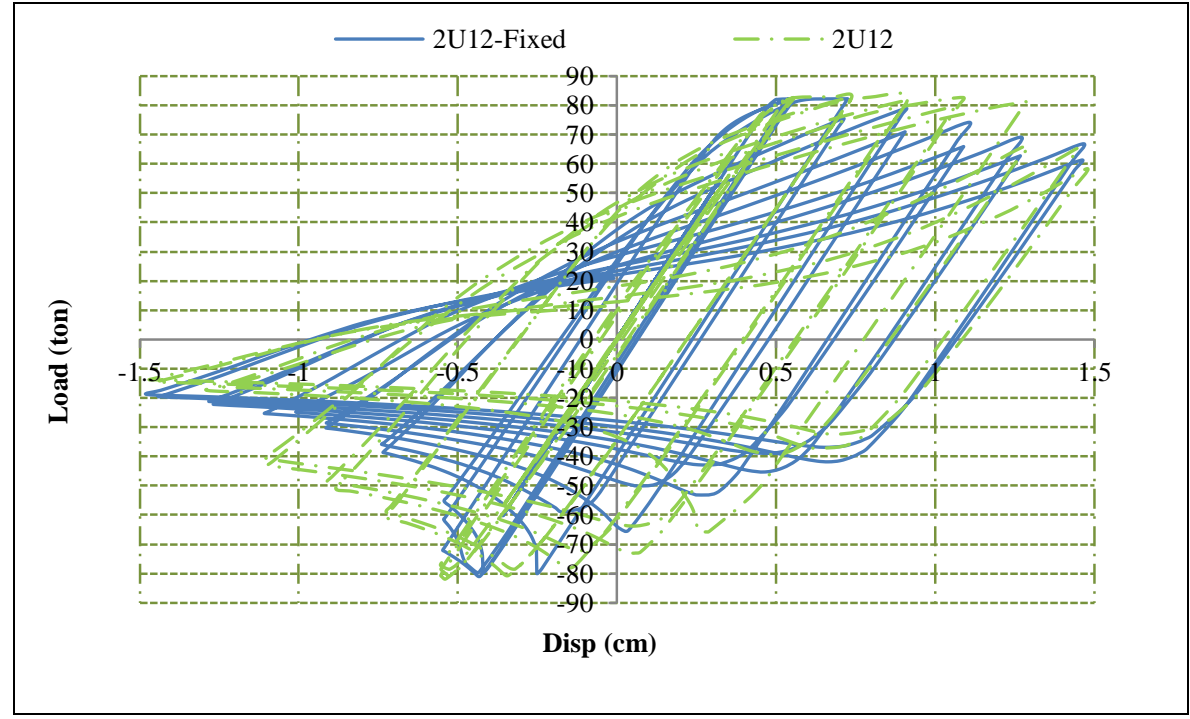

Figure 16. Comparison of $2 \mathrm{U} 12$ hysteresis curve with that of 2U12-Fixed

In Figures 17 and18, comparison between hysteresis curves of F5 and F5-Fixed and also between those of F20 with F20-Fixed are illustrated, respectively.

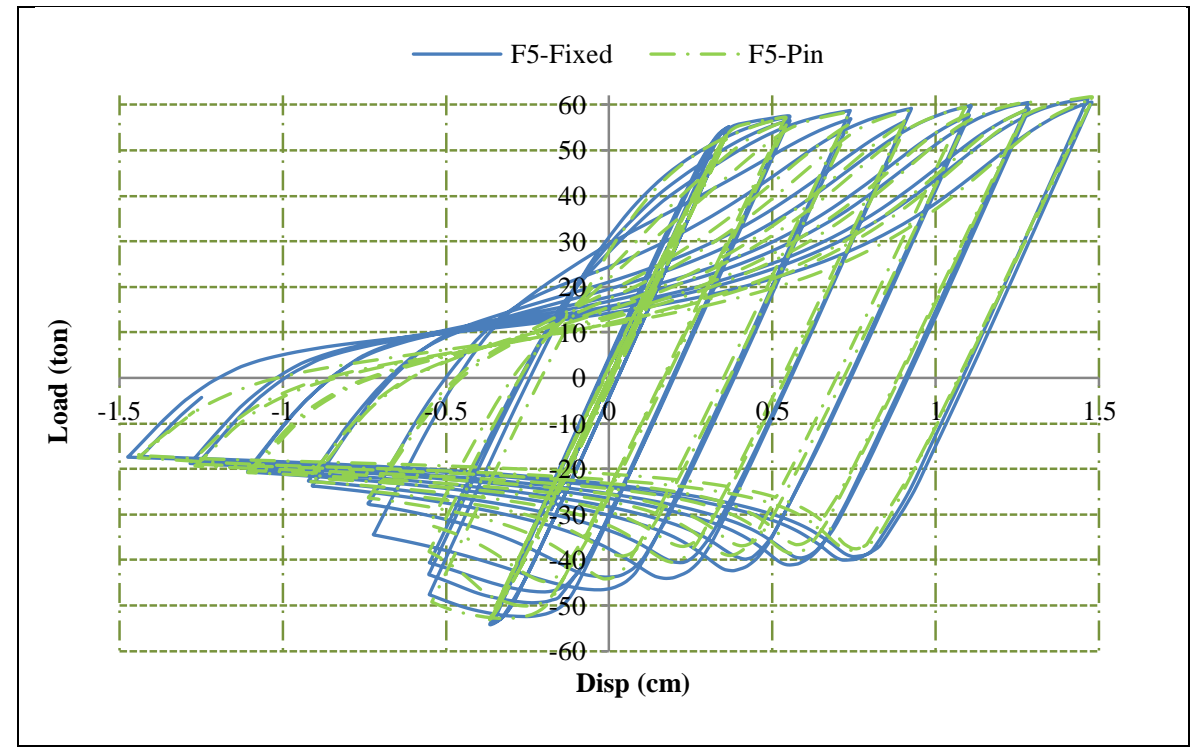

Figure 17. Comparison of $F 5$ hysteresis curve with that of F5-Fixed

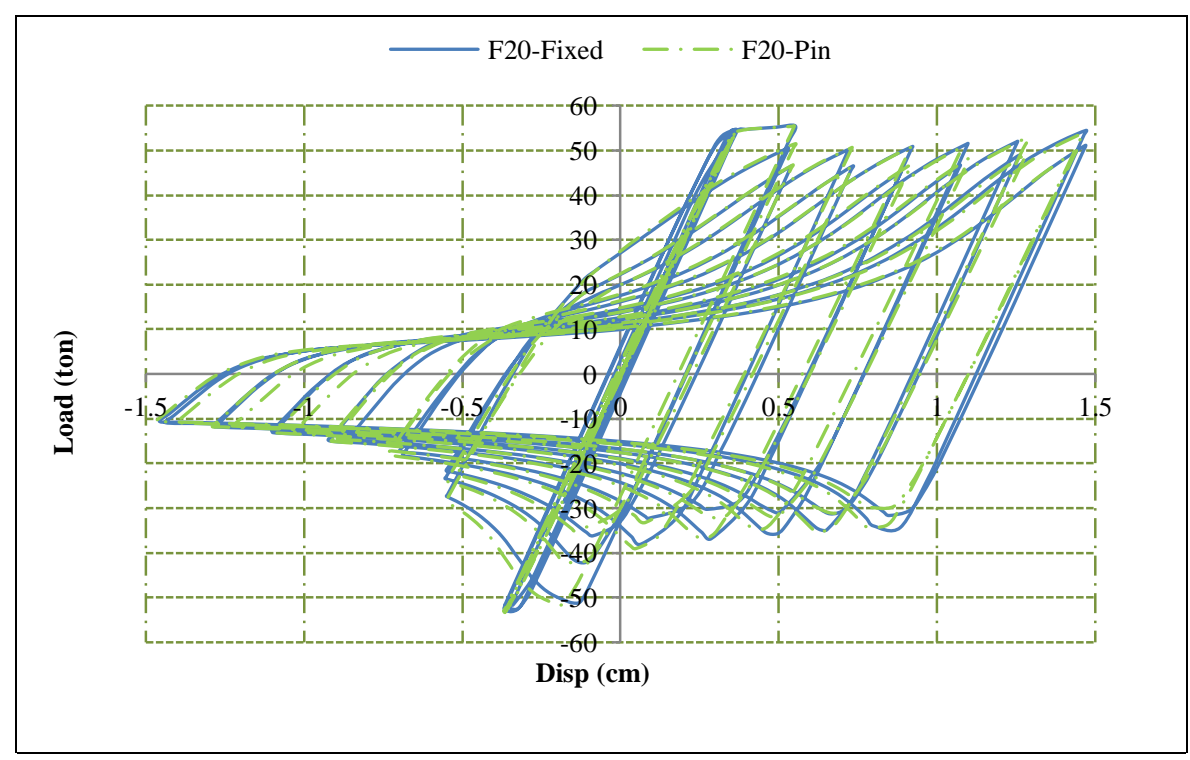

Figure 18. Comparison of F20 hysteresis curve with that of F20-Fixed 
F5 and F5-Fixed are buckled and yielded at the same load of 54.2 tons. The reason for buckling of these models was the significant reduction of $E_{p}$ with respect to $E_{e}$ after yielding and also substantial decrease in the buckling capacity of these models. The dissipated energy values of F5 and F5-Fixed were 826 tons.cm and 967 tons.cm, respectively. This means that the energy dissipation capacity of model has been increased up to $16 \%$ by changing the end condition from pinned to fixed. So for the model with $5 \mathrm{~cm}$ fuse length, changing the end condition has not affected its loading capacity but it can fatten hysteresis curve of this model and so increase its energy dissipation capacity. As shown in Figure 18 concerning F20 and F20-Fixed, both models have buckled and yielded at 54.2 tons and so end condition alternation has not affected their loading capacities. But changing the end condition in these models from pinned to fixed causes increased energy dissipation capacity up to $2 \%$, as F20 has dissipated the energy up to 726 tons.cm energies while this value was 742 tons.cm for F20-Fixed.

According to the mentioned results in this section, choice of fixed end condition for RCFs doesn't influence their loading capacity but it can improve their energy dissipation capacity. This means that in addition of better ductility, RCFs can have equal energy dissipation capacity with their proportional CBFs if their end condition is assumed as fixed and a proper fuse length is chosen for them.

\section{Conclusion}

Based on numerical studies of this paper, the following results have been concluded;

- F5 and F20 have better ductility and energy dissipation capacities than those of 2 U12 until the brace buckling.

- Significant reduction of Ep with respect to Ee causes early buckling of braces that their theoretical buckling capacity based on $P_{C r}=\pi^{2}$. $E / \lambda^{2}$ is more than their yielding capacity. In this study this issue has caused early buckling of RCF and so its ultimate loading capacity hasn't been achieved. Generally, this matter should be considered in design of all braces that have a theoretical buckling capacity more than their yielding capacity and for them the buckling capacity must be considered equal with their yielding capacity, otherwise it surely would cause mistake in design of braces, and that is a very concerning issue for the structure safety.

- Fuse length has no effect on the response of models until buckling, but after that F5 which has lower fuse length, acts well than F20 in terms of ductility and energy dissipation capacity.

- Based on the result of this study, this conclusion is gained that the longer length of fuse leads to the less intensity of the plasticity. In other words, the longer length of fuse is caused fuse reach later to its final plastic capacity and so fuse will be stop posterior.

- In this study the type of model end condition doesn't influence its loading capacity but for RCF models, their energy dissipation capacity increases when fixed condition is chosen for them. This increase in the energy dissipation capacity is significantly higher in F5 with respect to F20.

- Based on the result of this study for RCFs that have a theoretical buckling capacity more than their yielding capacity, the fixed end condition should be considered for them and also their fuse length should be $1 \%$ of the brace length.

- Generally, the RCFs which are designed properly have better ductility than CBFs while having equal energy dissipation capacities.

\section{References}

[1] Pall, A. S., and C. Marsh. "Response of friction damped braced frames."ASCE J.Struct Engng, 108(6) (1982): 1313. ISSN 00448001/82/0006-1313/\$01.00.

http://www.palldynamics.com/fr/pdf/40Pall_doc1.pdf.

[2] Jurukovski, D., and B. Simonov. "Effectiveness of energy absorbing elements in composite steel frame." Proceedings of the 9th World Conference on Earthquake Engineering (August 1988) Tokyo Kyoto, Japan.

[3] Sabouri-Ghomi, S. and A. Roufegarinejad. "Non-linear behavior of yielding damped braced frames." Struct. Design Tall Spec. Build. 14 (2005): 37-45. DOI: https://doi.org/10.1002/tal.257.

[4] Sabouri-Ghomi, S. and B. Payandehjoo. "Investigating the effect of stiffness and strength of each component on overall stiffness and strength of yielding damped braced core (YDBC)." J. Struct. Design Tall Spec. Build. 20 (2011): 747-756. DOI: https://doi.org/10.1002/tal.526.

[5] Jia, M., D. Lu, L. Guo, and L. Sun. "Experimental research and cyclic behavior of buckling restrained braced composite frame." J.Construct. Steel Res. 95 (2014): 90-105. DOI: https://doi.org/10.1016/j.jcsr.2013.11.021.

[6] Sabeli, R., S. Mahin, and C. Chang. "Seismic demands on steel braced frame buildings with buckling restrained braces." J. Eng. Struct. 25(5) (2003): 655-666. DOI: https://doi.org/10.1016/S0141-0296(02)00175-X. 
[7] Hoveidae, N., R. Tremblay, B. Rafezy and A. Davaran. "Numerical investigation of seismic behavior of short-core all-steel buckling restrained braces.” J.Construct. Steel Res. 114 (2015): 89-99. DOI: https://doi.org/10.1016/j.jcsr.2015.06.005.

[8] Maurya, A., M.R. Eatherton, R. Matsui and S.H. Florig. "Experimental investigation of miniature buckling restrained braces for use as structural fuses.” J.Construct. Steel Res. 127 (2016): 54-65. DOI: https://doi.org/10.1016/j.jcsr.2016.07.019.

[9] Moghaddam, H., and H. Estekanchi. "Seismic behavior of off-centre bracing systems.” J.Construct. Steel Res. 51(2) (1999): 177196.DOI: https://doi.org/10.1016/S0143-974X(99)00007-3.

[10] Bazzaz, M., Z. Andalib, A. Kheyroddin, and M.A. Kafi. "Numerical comparison of the seismic performance of steel rings in offcentre bracing system steel rings in off-centre bracing system." Steel Compos. Struct., Int. J. 19(4) (2015): 917-937. DOI: 10.12989/scs.2015.19.4.917.

[11] Bazzaz, M., A. Kheyroddin, M.A. Kafi, Z. Andalib, and H. Esmaeili. "Evaluating the seismic performance of off-centre bracing system with circular element in optimum place.” Int. J. Steel Struct. 14(2) (2014): 293-304. DOI: 10.1007/s13296-014-2009-x.

[12] D'Aniello, M., S. Costanzo, and R. Landolfo. "The influence of beam stiffness on seismic response of chevron concentric bracings.” J.Construct. Steel Res., 112 (2015): 305-324. DOI: https://doi.org/10.1016/j.jcsr.2015.05.021.

[13] Qu, B., F. Sanchez-Zamora, and M. Pollino. "Mitigation of inter-story drift concentration in multi-story steel concentrically braced frames through implementation of rocking cores." J. Eng. Struct. 70 (2014): 208-217. DOI: https://doi.org/10.1016/j.engstruct.2014.03.032.

[14] Qu, Z., A. Wada, S. Motoyui, H. Sakata, and S. Kishiki. "Pin-supported walls for enhancing the seismic performance of building structures.” J. Earthq Eng Struct Dyn. 41(14) (2012):2075-2091. DOI: https://doi.org/10.1002/eqe.2175.

[15] Kumar, A., D.R. Sahoo, and N. Kumar. "Limiting values of slenderness ratio for circular braces of concentrically braced frames." J.Construct. Steel Res. 115 (2015):223-235. DOI: https://doi.org/10.1016/j.jcsr.2015.08.026.

[16] Federico, G., R. Fleischman, and K. Ward. "Buckling control of cast modular ductile bracing system for seismic-resistant steel frames.” J.Construct. Steel Res. 71 (2012): 74-82. DOI: https://doi.org/10.1016/j.jcsr.2011.11.010.

[17] Ward, K.M, R.B. Fleischman, and G. Federico. "A cast modular bracing system for steel special concentrically braced frames." J. Eng. Struct. 45 (2012): 104-116. DOI: https://doi.org/10.1016/j.engstruct.2012.05.025.

[18] Legeron, F., E. Desjardins, and E. Ahmed. "Fuse performance on bracing of concentrically steel braced frames under cyclic loading.” J.Construct. Steel Res. 95 (2014): 242-255. DOI: https://doi.org/10.1016/j.jcsr.2013.12.010.

[19] Desjardins, E., F. Legeron, and E. Ahmed. "Performances of ductile fuses in reducing seismic demand on connections of concentrically steel braced frames" 15th World conference on Earthquake Engineering (Sep. 2012), Lisbon, Portugal.

[20] Bonetti, S.”Ductile fuses for special concentrically braced frames.” Ph.D. Dissertation, Kansas University, Kansas, US of America (2012).

[21] Shen, J., O. Seker, N. Sutchiewcharn and B. Akbas. "Cyclic behavior of buckling-controlled braces.” J.Construct. Steel Res. 121 (2016): 110-125. DOI: https://doi.org/10.1016/j.jcsr.2016.01.018.

[22] Seker, O. and J. Shen. "Developing an all-steel buckling controlled brace.” J.Construct. Steel Res. 131 (2017): 94-109. DOI: https://doi.org/10.1016/j.jcsr.2017.01.006.

[23] Momenzadeh, S., O. Seker, M. Faytarouni and J. Shen. "Seismic performance of all-steel buckling-controlled braces with various cross-sections.” J.Construct. Steel Res. 139 (2017): 44-61. DOI: https://doi.org/10.1016/j.jcsr.2017.09.003

[24] ABAQUS Ver .6.12. “User's Manual.” USA: RI (2012).

[25] AISC. "Specification for structural steel building, American Institute of Steel Construction." (2010). 